\title{
Sunphotometry of the 2006-2007 aerosol optical/radiative properties at the Himalayan Nepal Climate Observatory-Pyramid (5079 m a.s.l.)
}

\author{
G. P. Gobbi ${ }^{1}$, F. Angelini ${ }^{1}$, P. Bonasoni ${ }^{2}$, G. P. Verza $^{3}$, A. Marinoni ${ }^{2}$, and F. Barnaba ${ }^{1}$ \\ ${ }^{1}$ Institute of Atmospheric Sciences and Climate CNR, Rome, Italy \\ ${ }^{2}$ Institute of Atmospheric Sciences and Climate CNR, Bologna, Italy \\ ${ }^{3}$ Ev-K2-CNR Organization, Bergamo, Italy
}

Received: 3 December 2009 - Published in Atmos. Chem. Phys. Discuss.: 18 January 2010

Revised: 1 October 2010 - Accepted: 17 November 2010 - Published: 29 November 2010

\begin{abstract}
In spite of being located at the heart of the highest mountain range in the world, the Himalayan Nepal Climate Observatory (5079 $\mathrm{m}$ a.s.1.) at the Ev-K2-CNR Pyramid is shown to be affected by the advection of pollution aerosols from the populated regions of southern Nepal and the Indo-Gangetic plains. Such an impact is observed along most of the period April 2006-March 2007 addressed here, with a minimum in the monsoon season. Backtrajectoryanalysis indicates long-range transport episodes occurring in this year to originate mainly in the west Asian deserts. At this high altitude site, the measured aerosol optical depth is observed to be about one order of magnitude lower than the one measured at Ghandi College (60 ma.s.1.), in the IndoGangetic basin. As for Ghandi College, and in agreement with the in situ ground observations at the Pyramid, the fine mode aerosol optical depth maximizes during winter and minimizes in the monsoon season. Conversely, total optical depth maximizes during the monsoon due to the occurrence of elevated, coarse particle layers. Possible origins of these particles are wind erosion from the surrounding peaks and hydrated/cloud-processed aerosols. Assessment of the aerosol radiative forcing is then expected to be hampered by the presence of these high altitude particle layers, which impede an effective, continuous measurement of anthropogenic aerosol radiative properties from sky radiance inversions and/or ground measurements alone. Even though the retrieved absorption coefficients of pollution aerosols were rather large (single scattering albedo of the order of
\end{abstract}

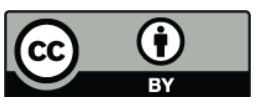

Correspondence to: G. P. Gobbi (g.gobbi@isac.cnr.it)
0.6-0.9 were observed in the month of April 2006), the corresponding low optical depths $(\sim 0.03$ at $500 \mathrm{~nm})$ are expected to limit the relevant radiative forcing. Still, the high specific forcing of this aerosol and its capability of altering snow surface albedo provide good reasons for continuous monitoring.

\section{Introduction}

The net radiative effect of anthropogenic aerosols currently present in the atmosphere is to cool the Earth system by increasing its albedo (e.g., Forster et al., 2007, Bellouin et al., 2008). However, some of these aerosols absorb radiation and warm the atmospheric layers they are suspended within. In highly polluted regions, dominance of the absorption effect can lead to a positive climate forcing, that is, a warming effect (Satheesh and Ramanathan, 2000; Ramanathan et al., 2007a, b; Nakajima et al., 2007; Ramanathan and Carmichael, 2008). As commonly intended, the term "forcing" indicates radiative effects of anthropogenic aerosol alone. Light absorption by aerosols is mainly due to the black carbon (BC) and organic particulate produced by the combustion of fossil fuels or biomasses. Air masses containing such aerosols are also referred to as atmospheric brown clouds (ABC, e. g., Ramanathan and Crutzen, 2003). Major sources of absorbing, $\mathrm{BC}$ aerosols are south and north America, Europe, central and south Africa, south and east Asia (e.g., Ramanathan and Carmichael, 2008).

In the Indian sub-continent, a positive aerosol forcing has been reported by several authors, e.g., at Kanpur in the Indo-Gangetic (IG) basin (Chinnam et al., 2006, Dey and Tripathi, 2008), in the wintertime at Manora Peak in the

Published by Copernicus Publications on behalf of the European Geosciences Union. 
Central Himalayas (Pant et al., 2006), and in Nepal (Ramana et al., 2004). A positive forcing was also observed in the aerosol-laden air proceeding from the Indian continent to the Maldives during the pre-monsoon (biomass burning) season, and proposed as a possible cause for the observed retreat of the Himalayan glaciers (Ramanathan et al., 2007a). In addition to pollution, the aerosol load of northern India and Nepal is affected by important natural contributions. Mineral dust from the surrounding West Asian deserts (or even from the Sahara and Arabian ones) can constitute a large fraction of the aerosol optical depth (AOD), particularly during the premonsoon season (March-May), when dust is observed to mix with anthropogenic pollution (e.g., Shresta et al., 2000; Chinnam et al., 2006; Prasad and Singh, 2007; Liu et al., 2008; Verma et al., 2008). In this context, the assessment of the radiative effects of anthropogenic vs. natural aerosols in this region represents an intricate task (e.g., Dey and Tripathi, 2008). Clouds add uncertainty to such assessment, since they constitute an important modulator of radiation, particularly important during the monsoon season (e.g., Liu et al., 2008).

Determination of the direct radiative forcing of aerosols essentially requires the knowledge of their scattering and absorption optical depths, plus ground albedo and scattering phase function (e.g., Haywood and Boucher, 2000; Schwartz, 1996; Charlson et al., 1992; Nakajima et al., 2007). In this respect, the magnitude of the radiative forcing is proportional to the AOD, and this latter is about an order of magnitude smaller at the high mountain sites with respect to the IG plains (e.g., Ramana et al., 2004, Pant et al., 2006). Sunpointing photometers provide spectral measurements of the $\mathrm{AOD}$, which is the sum of the scattering $\left(\mathrm{AOD}_{\mathrm{sca}}\right)$ and $\mathrm{ab}-$ sorption $\left(\mathrm{AOD}_{\mathrm{abs}}\right)$ components (e.g., Holben et al, 1998). Sky-scanning sunphotometers permit the separation of these two components and the measurement of the single scattering albedo $\left(\mathrm{SSA}=\mathrm{AOD}_{\mathrm{sca}} /\left(\mathrm{AOD}_{\mathrm{sca}}+\mathrm{AOD}_{\mathrm{abs}}\right)\right)$, e.g., Dubovik, and King, 2000. Over typical vegetated soil albedos, the switching from a negative (cooling) to a positive (warming) aerosol radiative forcing takes place for SSA descending below $\sim 0.9$ (i.e., for highly absorbing aerosols). This threshold rises to SSA $\sim 0.95$ (i.e., most of anthropogenic and mineral aerosols) over the highly-reflecting surfaces of snow and/or deserts (e.g., Haywood and Boucher, 2000).

The absorbing properties of aerosols reaching the Himalayan region have been studied by few authors: Wintertime large abundances of black carbon, BC $\left(1.36 \pm 0.99 \mu \mathrm{g} \mathrm{m}^{-3}\right.$ in December) observed by Pant et al. (2006) at Manora Peak (1950 ma.s.l.) in the central Himalayas was found to originate from the human activities in the adjoining valleys and to boundary layer transport. Since Manora Peak is located at $10 \mathrm{~km}$ from nearby valley villages laying at some $300 \mathrm{~m}$ a.s.l., such an impact is somewhat expected. Out of a two-year campaign carried-out both near Kathmandu and in the remote Nepalese Himalayas at $3920 \mathrm{~m}$ a.s.l., Carrico et al. (2003) observed aerosol concentrations minimizing during the monsoon season, to then steadily increase and peak from February to May. Particles were found to mostly originate from combustion and mineral dust sources. At the two sites, springtime BC averaged at $\sim 1.5 \pm 0.9$ and $0.5 \pm 0.4 \mu \mathrm{g} \mathrm{m}^{-3}$, respectively.

High aerosol absorption (SSA in the range 0.7-0.9) was reported by Ramana et al. (2004), during a winter 2002 campaign carried-out in Kathmandu and nearby locations. More remote conditions have been described by Shresta et al. (2000) who observed wintertime, pre- and early-monsoon accumulation of pollutants to occur also at the high elevation site of Phortse ( $4100 \mathrm{~m}$ a.s.l.), in the eastern Nepalese Himalayas Gokyo Valley. They attributed such condition to the regional circulation-transported pollutants from the IndianNepalese plains to this high Himalayan site.

The Nepal Climate Observatory at the Pyramid (NCO-P, http://evk2.isac.cnr.it), established in March 2006 at 27.9 N, $86.8 \mathrm{E}, 5079 \mathrm{~m}$ a.s.l. in the high Khumbu valley (Bonasoni et al., 2010), provided us with an opportunity to study such pollution-transport conditions by means of both sunphotometer and in situ observations of aerosol radiative and chemical properties at an even more remote location at the heart of the Himalayas (e.g., Fig. 1). The NCO-P was set up by the Ev-K2-CNR organization in the framework of the SHARE (Stations of High Altitude for Research on the Environment, http://www.evk2cnr.org/cms/en) and ABC-UNEP (http://www.rrcap.unep.org/abc/) programs. ISAC-CNR selected and installed the instrumentation for the atmospheric observations at the NCO-P, located at the top of a hill overlooking the Ev-K2-CNR Pyramid (Bonasoni et al., 2008). In this paper we analyse the first year of sunphotometer observations carried-out at the Observatory to identify the seasonal patterns of the aerosol column above this area and infer the main drivers of its radiative properties. To this aim, we shall also employ: (1) black carbon and aerosol size distribution measurements carried out at the NCO-P (e.g., Marinoni et al., 2010), (2) sunphotometer observations carried out at Ghandi College (GC), in the Indo-Gangetic plains, e.g., Fig. 1; (3) NOAA-Hysplit backtrajectories, (4) fires observations from the MODIS sensor onboard the NASA-Terra satellite, and (5) satellite aerosol observations retrieved by the orbiting CALIOP lidar.

\section{Methods}

\subsection{The sunphotometer}

Our automated Cimel CE-318 sunphotometer was installed at the NCO-P on March 27, 2006, as part of the AERONET network (Holben et al., 1998). The sunphotometer operates at seven wavelengths $(340,380,440,500,670,870$, 940 and $1020 \mathrm{~nm}$ ), performing both "direct sun" and "sky radiance" measurements. Data are continually sent via GMS Satellite to the AERONET headquarters at NASAGSFC for processing. Standard products of the sun-pointing 

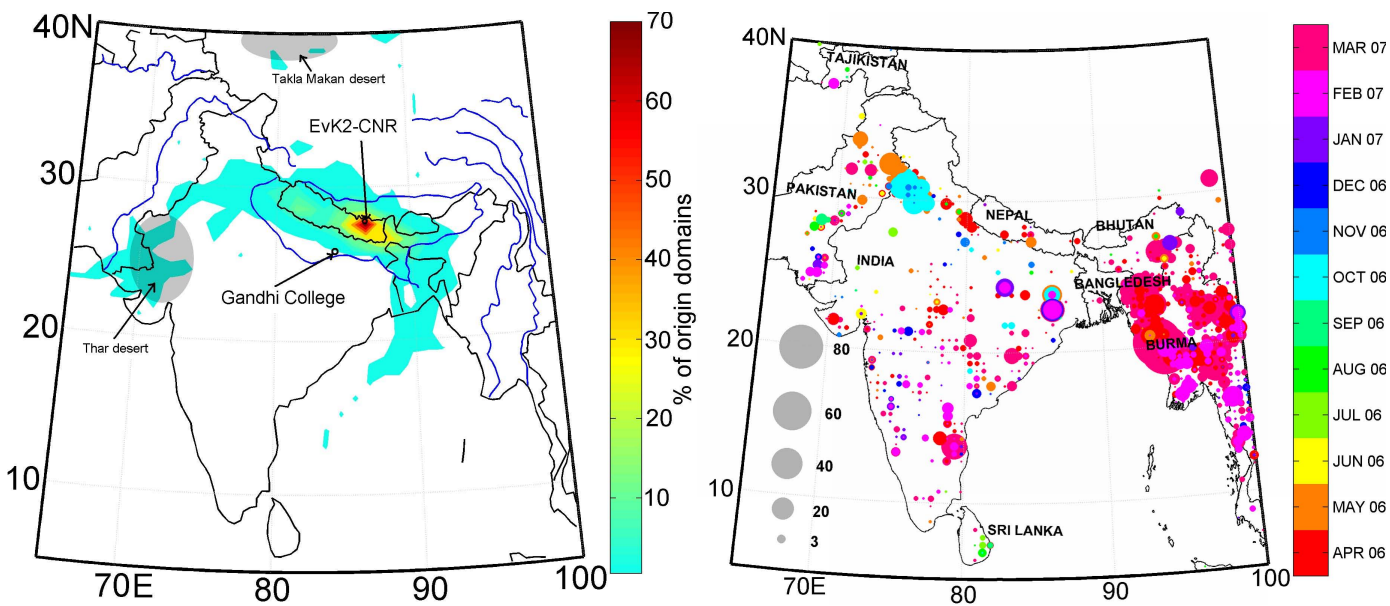

Fig. 1. (a) location of the Ev-K2-CNR (at NCO-P) and Ghandi College (GC) AERONET stations and (colour-coded) PBL transit density of all the backtrajectories ending $600 \mathrm{~m}$ a.g.l. at NCO-P in the period April 2006-March 2007 (see Sect. 2.2 for details on backtrajectories); (b): monthly averages of fire counts per $1000 \mathrm{~km}^{2}$ per day, as observed by MODIS Terra. Bullet size identifies the number of fires, colour code the relevant month.

data analysis are aerosol optical depths (AOD) and related Angstrom exponents at all the wavelengths, plus precipitable water (PW) (Holben et al., 1998), and aerosol fine mode optical depth $\left(\mathrm{AOD}_{\mathrm{FM}}\right)$ at $500 \mathrm{~nm}$ (O'Neill et al., 2003). In addition, inversion of almucantar measurements of sky radiance retrieves aerosol size distribution, asymmetry factor and single scattering albedo (SSA) (Dubovik and King, 2000). Accuracy of measurements is $\sim 0.01$ for the AOD observations and $\sim 0.1$ for $\mathrm{SSA}$ at $\mathrm{AOD}<0.2$ (Dubovik et al., 2000). Further details about the AERONET products and relevant retrievals are available at the web site http: //aeronet.gsfc.nasa.gov, where our measurements are accessible under the "Ev-K2-CNR" station page. A similar sunphotometer is installed by the AERONET at Ghandi College (GC, $26^{\circ} \mathrm{N}-84^{\circ} \mathrm{E}, 60 \mathrm{~m}$ a.s.l.) in the Gange's river plain, some $350 \mathrm{~km} \mathrm{SW}$ to NCO-P (e.g., Fig. 1). Ghandi College observations are employed here as a proxy of aerosol conditions in the Indo-Gangetic basin, a region we will show as of likely origin of the anthropogenic aerosol reaching the Himalayas.

\subsection{Backtrajectories}

Ten-day NOAA-Hysplit backtrajectories (http://www.arl. noaa.gov/HYSPLIT.php) have been computed to identify the near-ground origin of the air-masses reaching the NCO-P during the observational period. In this analysis, Hysplit rather than Lagranto backtrajectories (as in Bonasoni et al., 2010) have been used to exploit codes successfully developed to detect Saharan dust origin by accounting for airmass transits within the planetary boundary layer (PBL), e.g., Gobbi et al. (2004). In fact, PBL height is an output of the Hysplit model. Results of these runs include: (1) daily backtrajectory clusters ending at 300 and $600 \mathrm{~m}$ above the station at both 00:00 UTC (local 5:45 a.m.), and 12:00 UTC (local 5:45 p.m.), and (2) spatial density of all the back-trajectory transits within the PBL. We use this latter information to infer if transit of the air masses over a geographical region is potentially associated to an "entrainment" of local aerosols or pollutants, i.e., as a marker of the particulate matter origin. Backtrajectories are stopped when accumulating over $10 \mathrm{~mm}$ of rainfall (another Hysplit product) along their path. Since trajectories ending at $300 \mathrm{~m}$ and $600 \mathrm{~m}$ altitude resulted to be very similar, here we present the $600 \mathrm{~m}$ ones only. The origin density (percent of backtrajectories transiting within the PBL over 1 $\times 1$-degree geographical pixels) of all the backtrajectories ending at $600 \mathrm{~m}$ a.g.l. at NCO-P in the period April 2006-March 2007 is summarized in Fig. 1. The same figure illustrates the location of both desert regions (shaded areas) and fire events. The latters are given in terms of number, location and monthly distribution, as retrieved at a $1 \times 1$ - degree resolution from the space-borne MODIS sensor (e.g., http://neo.sci.gsfc.nasa.gov/).

\section{Results}

As in Bonasoni et al. (2010), we address as "pre-monsoon" the period 1 March-20 May, as "monsoon" the period 21 May-26 September, and as "post-monsoon" the period 27 September-20 November 2006. The period 21 November 2006-31 January 2007 is then defined as "winter season".

\subsection{Advection patterns}

Ten-day Hysplit backtrajectories for the four above-defined periods are presented in Fig. 2. Both the backtrajectory patterns as a function of arrival time (colour coded), and the trajectory origin densities are plotted (left and right columns, 

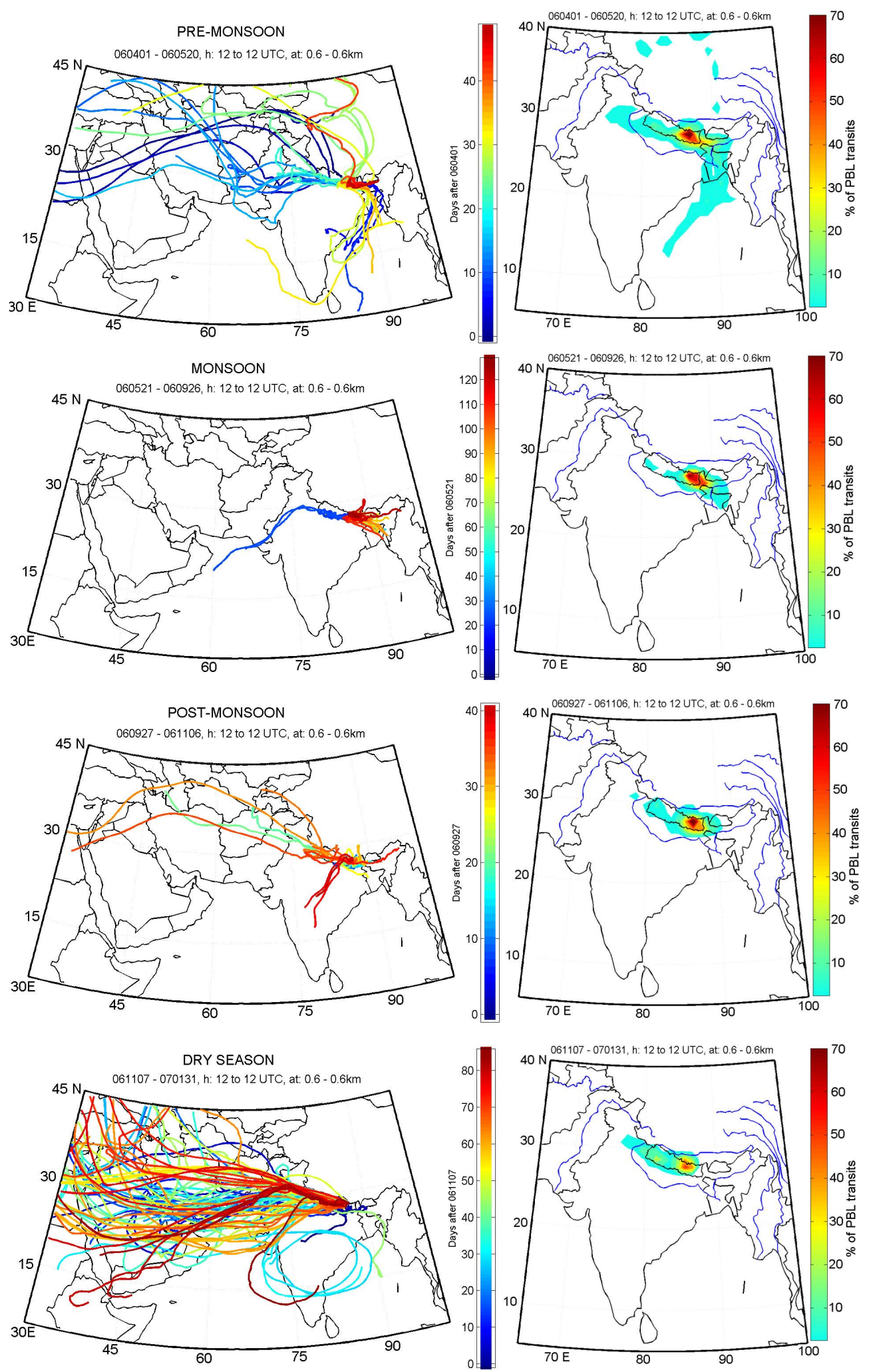

Fig. 2. Left column: daily patterns (colour-coded time scale) of back-trajectories ending at 12:00 UTC, 600 m above NCO-P during the 20062007 pre-monsoon, monsoon, post-monsoon, and winter season periods (first to fourth row, respectively). Right column: corresponding contour plots of the back-trajectories origin density (evaluated as percent of trajectory transits in the local PBL). 
respectively). Since the origin domains resulted to be much smaller than the full backtrajectory ones, a reduced geographical region is employed in the right column to represent all the source regions identified by our PBL-transit method. As anticipated by Fig. 1, this analysis shows that the most frequent PBL origin of airmasses reaching the NCO$\mathrm{P}$ is situated in Nepal and at its borders with India and Bangladesh. Lagranto backtrajectories provided very similar results (Bonasoni et al., 2010). With the exception of the monsoon period, backtrajectories show that some longrange transport episodes are also possible. However, the trajectory origin plots (right column in Fig. 2) indicate that at these furthermost distances trajectories tend to travel in the free-troposphere, i.e., not entering the PBL. A few (frequency $<10 \%$ ) mid-range trajectories appear to originate in the Takla Makan desert (end of April 2006), Thar desert (1-20 April 2006), and Bangladesh-Gulf of Bengal, during the pre-monsoon period. Trajectories indicating the possible Thar and Takla Makan deserts origin in the pre-monsoon period well agree with the dust advection patterns observed by Liu et al. (2008), and Gautam et al. (2009). However, the possibility that sub-grid transport processes not captured by back-trajectories could advect aerosols from far regions as the Arabic peninsula, and North Africa (e.g., Carrico et al., 2003) cannot be completely ruled out. An overview of dust transport episodes reaching NCO-P is given in a specific paper by Duchi et al. (2010).

With regard to biomass burning aerosols, Fig. 1 points out that fires (mostly due to agricultural practices) are set mainly in the period March-May and in October. In northern India, this practice is linked to the wheat-rice crop rotation performed in this area and generates large quantities of fine, BC rich aerosols (e.g., Badarinath et al., 2009). PBL backtrajectory origins for these two periods indicate that fire plumes are likely to be conveyed to NCO-P during the pre monsoon period from Northern India, Nepal and Bangladesh and, to a lesser extent, during the post monsoon from northern India. In the next section we shall verify the effectiveness of such transport patterns.

With the exception of a westerly transport in mid June, the monsoon season is characterized by short, rain-outinterrupted, back-trajectories mainly proceeding from E$\mathrm{SE}$ and originating in the eastern Nepal, east India and Bangladesh regions. A westerly, short-range circulation is re-established in the post monsoon. Trajectories then extend further to the west (up to north Africa and Europe) during the winter season. Still, the PBL-transit densities remain essentially confined to the Nepalese and northern India regions.

\subsection{The sunphotometer observations}

The statistics of the sunphotometer measurements at Ev-K2CNR for the period April 2006-March 2007 are reported in Table 1. This shows that $24 \%$ of level 1.0 (L1), unscreened measurements were rejected by the cloud-screening process
Table 1. Number of direct-sun measurements performed at Ev-K2CNR in the period April 2006-March 2007. L1 and L1.5 indicate unscreened and cloud-screened observations, respectively.

\begin{tabular}{llll}
\hline & L1 & L1.5 & L1.5/L1 \\
\hline Total Measures & 9345 & 7127 & 0.76 \\
Morning (a.m.) & 6699 & 5276 & 0.79 \\
Afternoon (p.m.) & 2646 & 1851 & 0.70 \\
Ratio a.m./p.m. & 2.28 & 2.85 & \\
\hline
\end{tabular}

leading to the 7127 level 1.5 (L1.5) observations discussed here. The AERONET cloud-screening (Smirnov et al., 2000) is based on two tests, both evaluating the temporal variability of measurements: (1) the triplet stability, and (2) the smoothness test. This links to the fact that clouds are characterized by both a large variability and high values of the AOD. The first test is applied to screen-out high frequency variability (of the order of one minute) by addressing the triplets (three acquisitions per wavelength, made $30 \mathrm{~s}$ apart) constituting each direct-sun AOD measurement. The measurement is discarded as cloud-contaminated if the AOD range within a triplet is higher than 0.02 (or higher than $0.03^{*} \mathrm{AOD}$, in cases of high AOD conditions as biomass burning or haze). The second test (diurnal stability) then checks if the standard deviation of the daily-averaged $500 \mathrm{~nm}$ AOD is less than 0.015 . If not, a "smoothness criterium" is applied by filtering-out AOD observations with time derivative larger than a given threshold. More details about the AERONET tests can be found in Smirnov et al. (2000). Kaufman et al. (2006) demonstrated that the AERONET cloud screening tends to overcorrect the aerosol dataset, i.e., to interpret aerosol conditions as clouds rather than the opposite. Such tendency was observed also in analysing data from northern India (Kanpur). On these premises, we believe the L1.5 data employed in our analysis can be considered as robustly cloud-screened. However, to exclude any possible contamination by cirrus clouds a further screening was performed by filtering-out the data with the 440-870 nm Angstrom exponents (AE) lower than 0.2. This threshold was selected according to the results presented in Gobbi et al. (2007), which demonstrate the Angstrom exponent of thin cloud layers with a coarse particle AOD fraction larger than $90 \%$ to be always less than 0.2. This filtering reduced by $\sim 22 \%$ (from 853 to 665 ) the L1.5 monsoon season measurements and by $\sim 9 \%$ (from 7127 to 6483) the remaining observations.

Due to anabatic winds and consequent formation of afternoon clouds, the number of morning measurements at EvK2-CNR was on average 2.85 times the post-meridian one. Both the number of L1 daily measurements and percentage of L1.5 data during the five periods are illustrated in Fig. 3. An instrument failure caused the measurements gap visible in the period 11-24 February 2007. Because of significant cloud contamination and rain conditions, both the number 


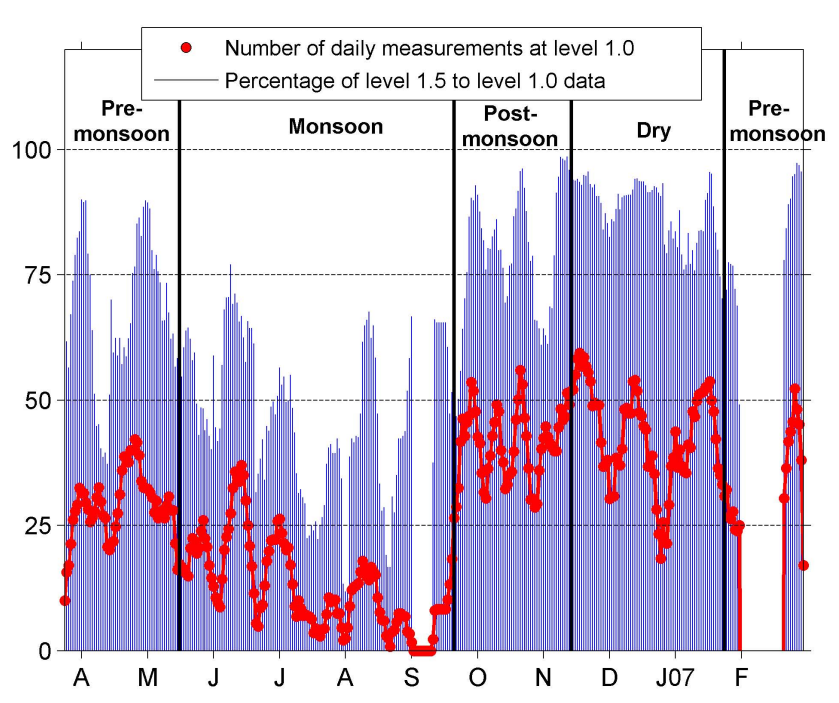

Fig. 3. Number of L1 sunphotometer measurements per day at the Ev-K2-CNR (red dots) and percent of cloud-screened, L1.5 data (blue bars) in the period April 2006-March 2007.

of observations and inverted retrievals become rather small during the monsoon season, in particular between July and September. However, the number of L1.5 observations in this period is of the order of 100 /month, a quantity we believe adequate to provide a meaningful AOD statistics.

Monthly medians of $500 \mathrm{~nm}$ AOD (also showing contribution of fine-mode particles, $\mathrm{AOD}_{\mathrm{FM}}$ ) and precipitable water (PW) data at both Ev-K2-CNR and GC are presented in Fig. 4 (top and bottom row, respectively). PW and AOD levels at Ev-K2-CNR are about one order of magnitude smaller than at GC, with typical wintertime AOD of the order of 0.05 and 0.8 , respectively. To provide a comparison, the $3400 \mathrm{~m}$ a.s.l. background station of Mauna Loa (Hawai) recorded an average $500 \mathrm{~nm} A O D=0.011$ and $\mathrm{PW}=0.17 \mathrm{~cm}$ in January 2007 and AOD $=0.013$ and $\mathrm{PW}=0.35 \mathrm{~cm}$ in August 2006. The PW records of Ev-K2-CNR and GC reveal the beginning and end of the wet, monsoon season (mid-May, end of September 2006, respectively) to proceed in phase at both stations. Conversely, total AOD at NCO-P follows a seasonal cycle markedly different from the GC one, presenting a maximum in the summer (monsoon) season, mostly attributable to coarse-particle extinction. This does not occur at Ghandi College, where the AOD maximizes both in spring (mixture of fine (pollution) and coarse (mineral dust) particles (e.g., Chinnam et al., 2006; Prasad and Singh, 2007), and in winter (mostly fine mode pollution), while minimizing in summer (likely due to the monsoon rainout effect, e.g., Carrico et al., 2003). Therefore, the coarse particle-driven summer maximum observed at NCO-P cannot be related to the advection of mineral dust from the IG plains. Neither can it be attributed to cirrus clouds since MODIS cirrus reflectance statistics (http://disc.sci.gsfc.nasa.gov/giovanni\# maincontent) present a minimum during this very season. We shall investigate the possible origins of such phenomenon in the next section. Finally, it is worth noticing the similarity in the fine mode AOD time patterns of the two stations, where the monsoon rain-out effect results into a concurrent $\mathrm{AOD}_{\mathrm{FM}}$ minimum in July.

As pointed out in the discussion of Table 1, the number of afternoon measurements was smaller than the morning one because of clouds generated by anabatic winds (see also Bonasoni et al., 2010). Figure 5 summarizes the impact of such oscillation on various parameters observed at NCO-P. The am vs. pm (with respect to local noon) behaviour of the median $\mathrm{AOD}, \mathrm{AOD}_{\mathrm{FM}}$ and $\mathrm{AOD}_{\mathrm{FM}} / \mathrm{AOD}$ at Ev-K2-CNR reported in Fig. 5 confirm an impact of the valley breeze regime on the air column above NCO-P. In fact, the pm AOD ${ }_{\mathrm{FM}}$ (Fig. 5b) is larger than the am one in the months of highest BC advection: January to April and October (Fig. 5d). The same is not always observed in the total AOD, which will be shown to be affected by the presence of elevated, coarse particle layers. At ground level, the valley breeze regime is found to bring pollutants (such as BC and PM1) to the NCO-P all year round, with minor strength during the monsoon period (e.g., Marinoni et al., 2010). BC observations reported in Fig. 5d evidenced: (a) maximum BC levels in the months of April and October 2006, plus in January, February and March 2007; and (b) an afternoon to morning BC ratio always of the order of two or larger, with the exception of the monsoon period when, however, it remained larger than one. In this respect, it is worth remembering that April and October are periods of maximum biomass residues burning in the IG region (e.g., Fig. 1). The backtrajectory patterns of Fig. 2 confirm aerosols from this region are likely advected to the NCO-P during these periods.

In Fig. 6a we compare the $500 \mathrm{~nm}$ AOD daily-averaged time series to daily-averaged, $500 \mathrm{~nm}$ aerosol extinction coefficients $\left(\sigma_{\text {ext }}\right)$, as computed from concurrent in-situ aerosol size-distributions data from the NCO-P optical particle counter (e.g., Marinoni et al., 2010). The $\sigma_{\text {ext }}$ have been calculated by Mie theory, assuming a refractive index $m=1.5-0.001$ i. According to the following analysis, the AOD vs. $\sigma_{\text {ext }}$ comparison can provide information on the altitude dependence of the aerosol content. The plots in Fig. 6 show the two variables to be anti-correlated during the monsoon season, when the total AOD reaches maximum yearly values and $\sigma_{\text {ext }}$ minimum ones, both about an order of magnitude above/below the pre-monsoon levels. In Fig. 6a we also report the aerosol scale height $H_{\mathrm{a}}$, a parameter used to characterize the commonly observed exponential decrease with height $(z)$ of the aerosol extinction: $\sigma_{\text {ext }}(z)=\sigma_{\text {ext }}(0)$ $\exp \left(-z / H_{\mathrm{a}}\right)$, (e.g., Guibert et al., 2005; Gobbi et al., 2004). For such a vertical distribution, the integral over $z$ of $\sigma_{\text {ext }}(\mathrm{z})$, i.e., the AOD, is linked to the ground extinction $\sigma_{\text {ext }}(0)$ by the simple relationship (e.g., Tomasi, 1982; Kaufman and Fraser, 1983):

$H_{\mathrm{a}}=\mathrm{AOD} / \sigma_{\mathrm{ext}}(0)$ 

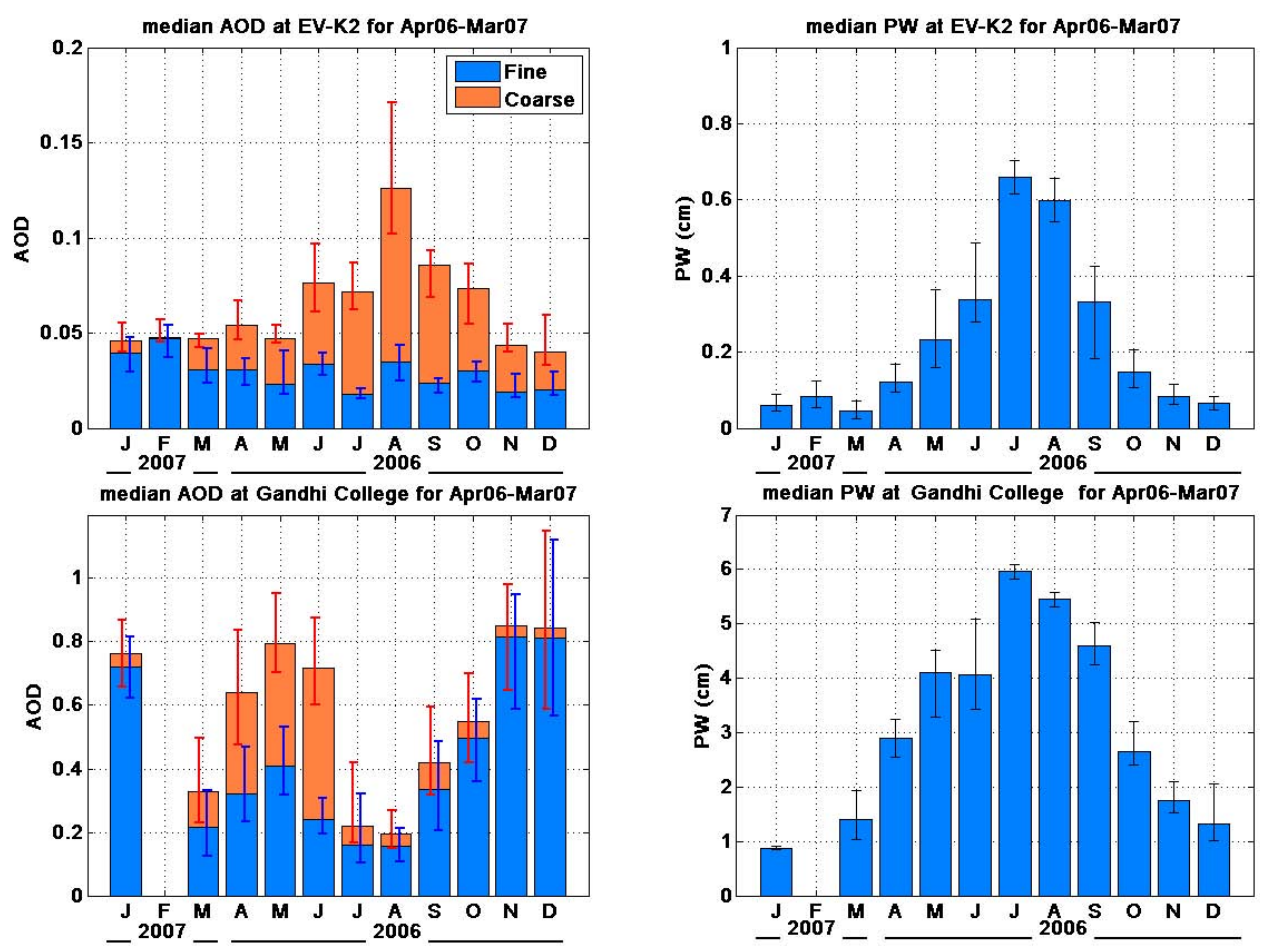

Fig. 4. Monthly median sunphotometer observations collected in the period April 2006-March 2007 at Ev-K2-CNR (top row) and Ghandi College (bottom row). L1.5, cloud-screened $500 \mathrm{~nm} \mathrm{AOD,} \mathrm{and} \mathrm{contribution} \mathrm{of} \mathrm{fine-mode} \mathrm{particles,} \mathrm{AOD} \mathrm{FM} \mathrm{(blue} \mathrm{element} \mathrm{of} \mathrm{bars)} \mathrm{are} \mathrm{plotted}$ in the left column, while precipitable water (PW) plots are in the right column. Thin lines span the 25th-75th percentile intervals.

It is worth noticing that $H_{\mathrm{a}}$ is also the height a vertically mixed aerosol (i.e. characterized by a constant extinction coefficient $\sigma_{\text {ext }}(0)$ with height) would reach to generate the optical depth AOD. Therefore, $H_{\mathrm{a}}$ can be also considered as an equivalent mixing height.

$H_{\mathrm{a}}$ error bars in Fig. 6 represent the range over which $H_{\mathrm{a}}$ varies when using in (1) $\sigma_{\text {ext }}(0)$ computed with refractive index $m=1.40-0.0001 \mathrm{i}$ (lower end), and $m=1.60-0.01 \mathrm{i}$ (upper end). This range includes most of the aerosol conditions encountered in the atmosphere. This sensitivity test shows that the high $H_{\mathrm{a}}$ variability evidenced in Fig. 6 requires other causes than particle composition to be explained.

Typical tropospheric values of $H_{\mathrm{a}}$ lay in the range 0.3$3 \mathrm{~km}$. Here at NCO-P we notice $H_{\mathrm{a}}$ to attain values smaller than $10 \mathrm{~km}$ only during the pre-monsoon season, to reach values of over $100 \mathrm{~km}$ during the monsoon, and start declining back to less than $10 \mathrm{~km}$ only past November 2006 . In this respect, it is interesting to observe that the break in the monsoon occurred in the period 12-23 June 2006 (evidenced here by the blue backtrajectories in Fig. 2b, and discussed in Bonasoni et al., 2008) led to an aerosol $\sigma_{\text {ext }}$ increase at the ground and to a consequent decrease of $H_{\mathrm{a}}$ below $10 \mathrm{~km}$. Together with the previous AOD discussion, this behaviour of $H_{\mathrm{a}}$ indicates that it is elevated layers that cause the coarse particle AOD increase during the monsoon, and in some cases in the post-monsoon and winter seasons at NCO-P. Since cloud-screening was shown to be robustly implemented, and cirrus clouds minimize in summer, this coarse particle AOD is possibly attributable to ice crystals or dust blown off the surrounding mountain ridges or to hydrated/cloud-processed aerosols (e.g., Koren et al., 2007). Both hypothesis are likely since the monsoon season is characterized by: (1) a near $180^{\circ}$ wind rotation at 5000$8000 \mathrm{~m}$ a.s.l., leading to airmasses blowing directly from ESE (i.e., from the top peaks in the Mt. Everest region) over the NCO-P (see also Fig. 2), and (2) by continuous cloud formation and dissolution. The smoothness of the transition from monsoon to post monsoon AOD (October) supports such meteorology-dependent interpretation of the phenomenon.

Daily averages of the $440-870 \mathrm{~nm}$ Angstrom exponents (AE), together with the $440 \mathrm{~nm}$ aerosol single scattering albedo (SSA is not retrieved by AERONET at $500 \mathrm{~nm}$ ) recorded at NCO-P and GC are plotted in Fig. 6b. At both stations, SSA measurements are very few in the monsoon period. This is due to a lack of the $360^{\circ}$ clear sky conditions needed to perform almucantar observations. This scarcity of inversion data over a large portion of the year prevents from determining a robust SSA statistics. Commenting some of the retrieved data is nevertheless interesting. In Fig. $6 \mathrm{~b}$ we notice a rather stable behaviour of the SSA at GC (green diamonds), maintaining an average value of the order of $0.9 \pm 0.05$ along the whole year. Conversely, SSA at Ev-K2-CNR (magenta stars) attains such values only in a 

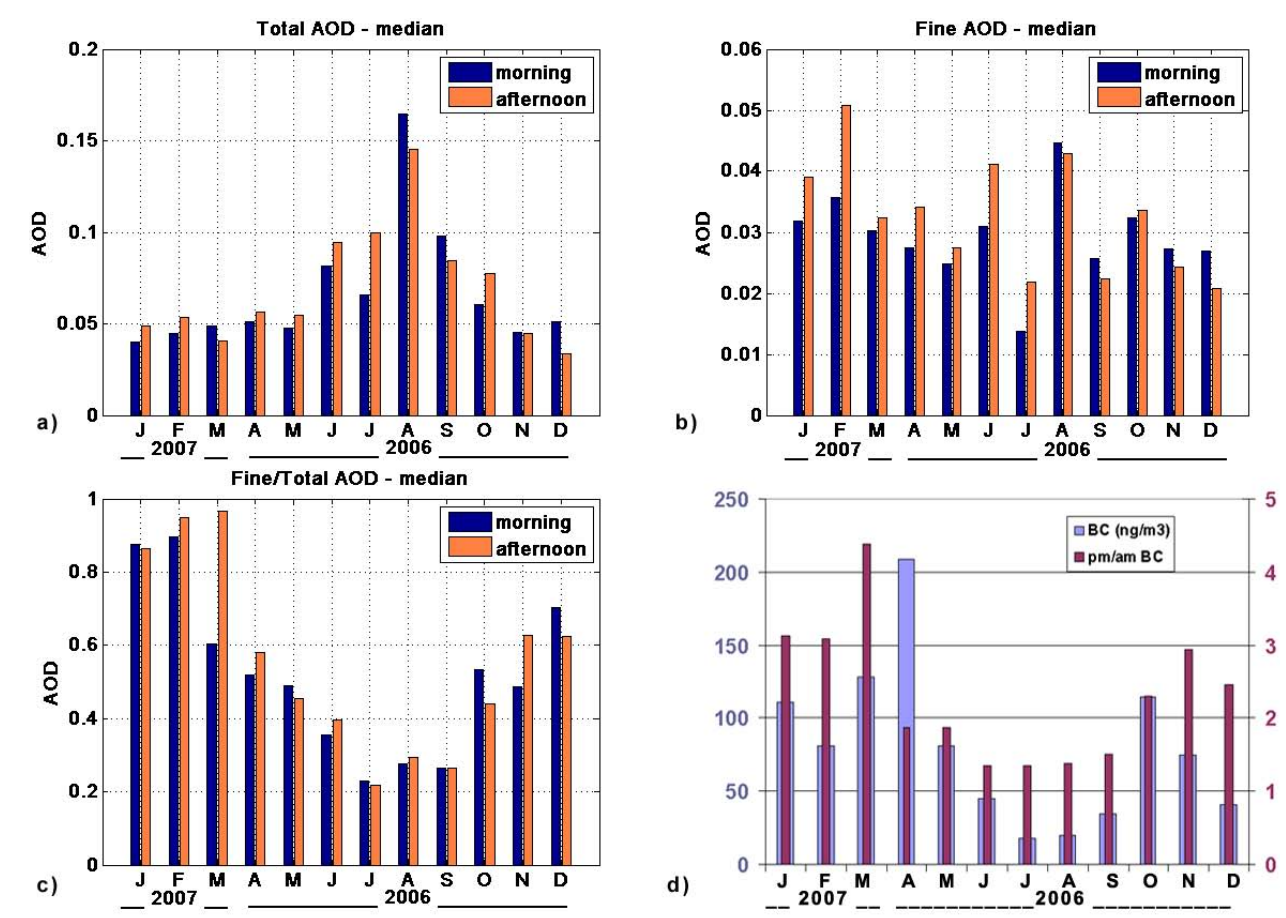

Fig. 5. Ev-K2-CNR monthly medians of morning (blue bars) and afternoon (orange bars) sunphotometer observations of: (a) total AOD, (b) fine mode AOD, (c) fine to total AOD ratio. In (d) purple bars report the median black carbon content (ng/ $\mathrm{m}^{3}$, left axis) and the afternoon/morning black carbon ratio (red bars, right axis) measured at ground level at NCO-P.

few days of the pre-monsoon season, while decreasing to unrealistically low values from the onset of the monsoon until the winter season. As guessed before, such unrealistic values in the SSA retrievals can be attributed to the presence of "giant" (over $20 \mu \mathrm{m}$ ) particles the inversion algorithm is unable to reproduce. In fact, such condition leads the algorithm to attributing the relevant extinction to absorption processes, i.e., to a lowering of the SSA (Oleg Dubovik, personal communication, 2009).

Figure $6 \mathrm{~b}$ also shows the Angstrom exponent records of the two stations to systematically depart from each other in the monsoon season, when the $\mathrm{AE}$ decreases to low values at NCO-P, while remaining high at GC. Since monsoon clouds affect both stations (as evident from correlated measurement gaps) and the cloud screening procedure for the two data set is the same, this differing behaviour confirms it is not incomplete cloud-screening the reason for the lowering of the $\mathrm{AE}$ at NCO-P. Conversely, these evidences support local phenomena as the wind-blown or hydrated/cloud-processed aerosol as origin of the coarse particle AOD increase observed in the air column above NCO-P during the monsoon and postmonsoon seasons.

In early April and early May 2006, high Angstrom exponents (i.e., $\mathrm{AE}>1.5$ ) and low $H_{\mathrm{a}}$ values do indicate the AOD (of the order of 0.03 at $500 \mathrm{~nm}$ ) to be determined essentially by fine particles in the lower atmosphere. In these periods, the SSA of Fig. $6 \mathrm{~b}$ present values in the range 0.60.9 , i.e., consistent with minimum SSA values obtained at
NCO-P by Marcq et al. (2010), and coinciding with the maximum in BC reported in Fig. 5d. These conditions indicate that in polluted days column SSA values as low as 0.6-0.7 $( \pm 0.1)$ might characterize aerosols at NCO-P. In fact, high aerosol absorption (SSA 0.78) was also observed by Ramana et al. (2004) during a winter campaign carried-out in Kathmandu and nearby locations.

According to the picture established so far, elevated coarse particles are often more important than near-ground aerosols at determining the AOD and the related radiative effects at NCO-P. The radiative impact of anthropogenic aerosols (essentially low level fine particles) results then difficult to assess from sunphotometry and ground measurements alone. This is particularly true during the monsoon season. Low values of the Angstrom exponent, together with the $\mathrm{AOD}_{\mathrm{FM}} / \mathrm{AOD}$ ratio can however help detecting the occurrence of such conditions. When observed, pollution aerosols (as identified by backtrajectories and high Angstrom exponents) exhibited high absorption characteristics, with SSA ranging from $\sim 0.9$ down to $\sim 0.6$. As indicated in the introduction, such SSA levels lead to an atmospheric warming effect over most ground albedoes (Haywood and Boucher, 2000). In fact, the absolute value of this atmospheric forcing is expected to be moderated by the very low values of the relevant AODs. (e.g., Pant et al., 2006). 


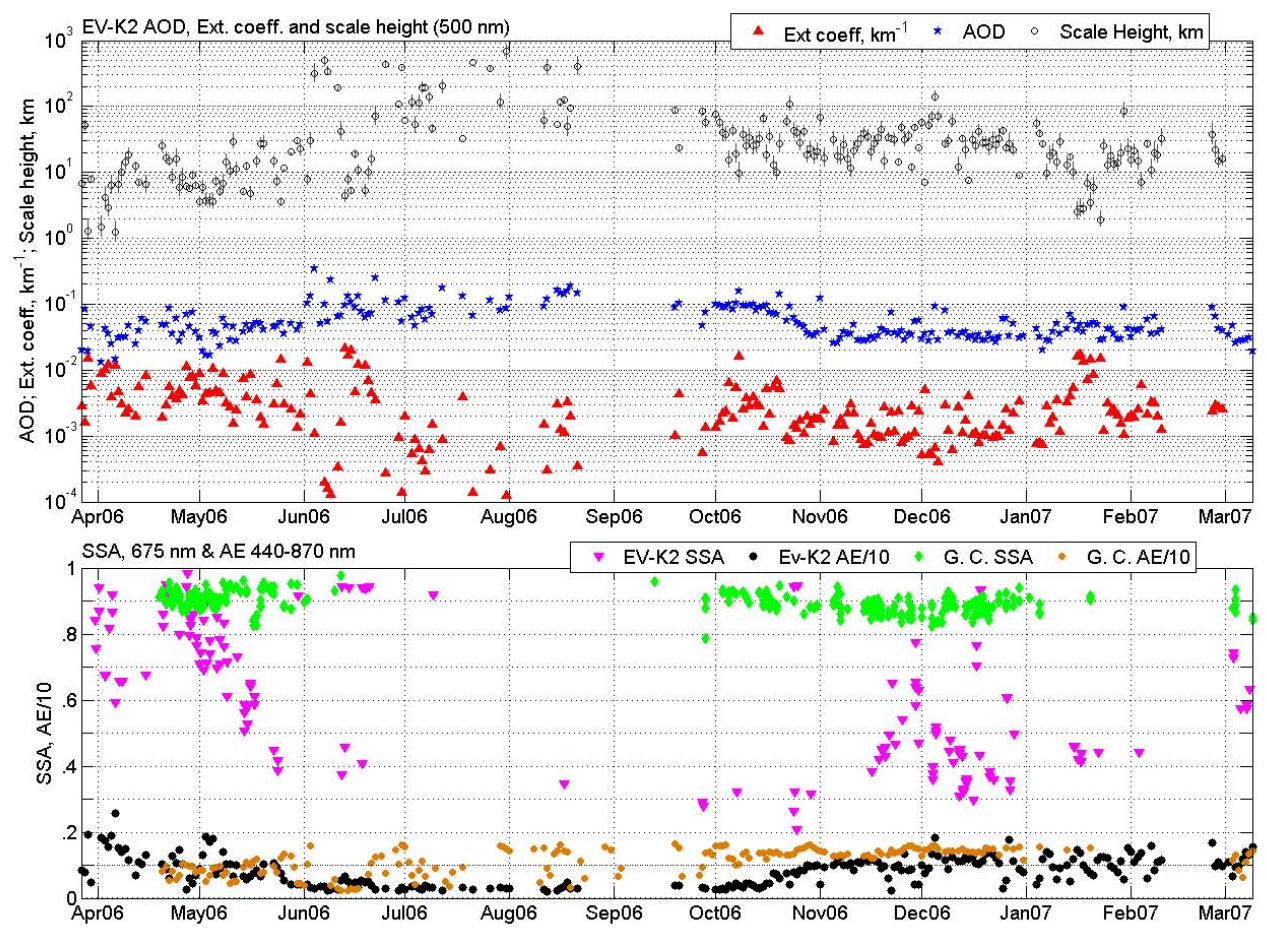

Fig. 6. (a) daily-average values of: $500 \mathrm{~nm}$ AOD (blue stars); $500 \mathrm{~nm}$ ground aerosols extinction coefficient (red triangles), and aerosol scale height $H_{\mathrm{a}}$ (black circles) observed at the NCO-P. $H_{\mathrm{a}}$ error bars represent its variability for refractive index ranging from $m=1.40-0.0001$ (lower end) to $m=1.60-0.01 \mathrm{i}$ (upper end); (b) daily-average values of: the 440-870 nm Angstrom exponent (AE, divided by 10) at Ev-K2CNR (black dots) and at Ghandi College (orange circles), and $440 \mathrm{~nm}$ aerosol single scattering albedo at Ev-K2-CNR (magenta stars), and at Ghandi College (green diamonds).

\subsection{The altitude-resolved picture from satellite observations}

To support the discussion of ground-based measurements presented so far we used observations from the CALIOP lidar onboard CALIPSO (the NASA-CNES Cloud-Aerosol Lidar and Infrared Pathfinder Satellite Observations) launched in April 2006 (Winker et al., 2007). These provide an opportunity to look into the season-dependent vertical distribution of aerosols and thin clouds in this region. Since CALIOP observations started in June 2006, we miss such information for the pre-monsoon period. In Fig. 7 we show profiles from CALIPSO transects crossing within $200 \mathrm{~km}$ from NCO-P. The CALIOP lidar backscatter signals from the $532 \mathrm{~nm}$ cross and parallel-polarized channels are both plotted (left and right columns, respectively). Since spherical aerosols do not depolarize the laser beam they backscatter, the cross-polarized lidar signal is essentially originated by non-spherical particles as ice crystals and mineral dust (e.g., Gobbi et al., 2004). The image pairs of Fig. 7 then provide a picture of the shape-dependent aerosol load along each transect. Two principal features result from the CALIOP record: (1) the common piling-up of aerosols against the Himalayas, and (2) the recurrent presence of clouds over the mountain range.
Figure 7a and b report 13 June and 25 June 2006 profiles, respectively. In spite of the ongoing monsoon season, the period of 12-23 June presented a shift in circulation (from SE to NW, e.g., Fig. 2) resulting into a break of the monsoon. This brought clear skies and pollution build-up against the Himalayas, as shown in Fig. 7a, and confirmed by the extinction and scale height records in Fig. 6. Typical monsoon conditions, with extended cloud and cirrus cover over the whole transect where re-established on June 25 (Fig. 7b).

Formation of lee-wave-like clouds above the Himalayas, following the uplift of polluted airmasses from the IG plain in the early post-monsoon season (6 October 2006), is depicted in Fig. 7c. In this case, presence of pollution and clouds is accompanied by an increase in ground extinction and a reduction in $H_{\mathrm{a}}$ at NCO-P (Fig. 6). However, the persistent small values of $\mathrm{AOD}_{\mathrm{FM}}$ in the period October-December 2006 (e.g., Fig. 4), together with concurrent high aerosol scale heights, indicate that cloud conditions as of Fig. 7c can also be common during the post-monsoon and winter seasons. Presence of pollution on the IG plains and cirrus clouds over the Himalayas is also detected by the 27 February 2007 (pre-monsoon) CALIOP transect of Fig. 7d.

As mentioned, one interesting outcome of the CALIOP profiles is the detection, in non-monsoon periods, of aerosols piling-up from the IG plains towards the Himalayan foothills 

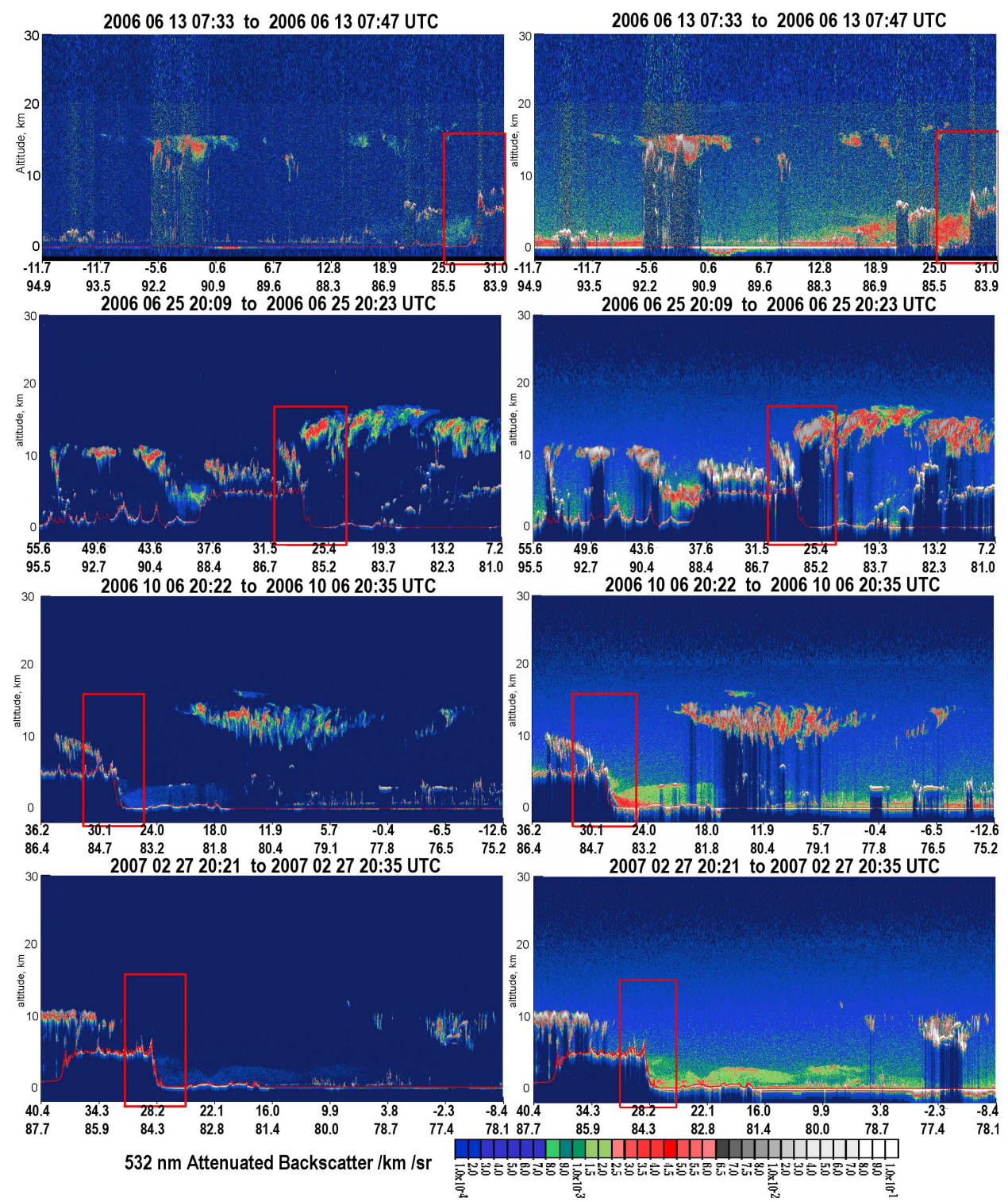

Fig. 7. CALIOP lidar transects across the Hymalayas on June 13, 2006 (a), 25 June 2006 (b), 6 October 2006 (c), and 27 February 2007 (d). The first lines of abscissa labels indicate the latitude, the second the longitude. Cross and parallel-polarized lidar returns (in terms of attenuated backscatter coefficients) are presented in the left and right columns, respectively. The Himalayan region of interest is evidenced by a red box.

(e.g., Figs. 5c, 5d, and 7a). This mechanism generates an impressive pollution "wave" the mountain range gets impacted by (along the trajectories illustrated in Fig. 2) and helps venting into the free troposphere. This also explains the very high concentration of black carbon $\left(>1 \mu \mathrm{g} / \mathrm{m}^{3}\right)$ often observed at the NCO-P in the pre-monsoon season (e.g., Figure 5, and Marinoni et al., 2010). During winter the depth of the pollution layer decreases as a consequence of reduced convection. However, Fig. 7 together with backtrajectories of Fig. 2 and $\mathrm{AOD}_{F F}$ in Fig. 4 show that also in the cold season polluted air masses can travel from the IG plains to and over the remote, high altitude location of NCO-P.

\section{Conclusions}

The first year-round sunphotometer observations carried out at the high altitude (5079 $\mathrm{m}$ a.s.1.) Himalayan Nepal Climate Observatory-Pyramid showed both total AOD and PW cycles to maximize during the monsoon season (May-September 2006, median $500 \mathrm{~nm}$ AOD 0.08) and minimize (median AOD 0.04) in winter. Conversely, the AOD of fine mode particles was observed to minimize at $\sim 0.025$ during the monsoon and maximize in winter at $\sim 0.04$. These AOD values are higher than the ones observed at the $3400 \mathrm{~m}$ a.s.l., background station of Mauna Loa (Hawaii) in the same 
periods: $\sim 0.013$ and $\sim 0.011$, respectively. The monsoon AOD maximum at Ev-K2-CNR is found to be caused mainly by large, supermicron particles not observed at the ground. Conversely, in the Indo-Gangetic basin, some $300 \mathrm{~km} \mathrm{SW}$ to NCO-P, the Ghandi College sunphotometer observed AOD to minimize during the monsoon, with most of the optical depth generated by fine mode, submicron particles. In this respect, similarities are found between the fine mode AODs at the two stations, while the NCO-P coarse mode summer AOD maximum appears to be uncoupled from IG-plains emissions. This uncoupling was unexpected since backtrajectories indicate the NCO-P to be influenced by transport from the plains of Nepal and northern India during most of the year.

Aerosol scale heights computed at NCO-P confirmed that it was elevated particle layers that regularly contributed at determining the variable coarse particle AOD. Based on the robustness of the cloud-screening processes, on the meteorological patterns, and on the low AODs. associated to these events, such contribution was attributed to wind-blown ice or mineral particles as well as to hydrated/cloud-processed aerosols. The dual contribution to the AOD (from both low and elevated particle layers) complicates the assessment of the aerosols radiative forcing in this region by hampering the retrieval of correct radiative parameters of the anthropogenic component from sunphotometry and/or ground measurements alone.

During the monsoon season, the number of sky radiance inversions to retrieve aerosol SSA was extremely low, thus impeding the make of a robust year-round statistics. When retrievable, the SSA of fine mode, possibly anthropogenic aerosols (according to high Angstrom coefficients and backtrajectories) resulted to be mostly below the threshold of 0.9 , with minima of the order of 0.6 , i.e., conditions certainly leading to a positive (warming) radiative forcing (Haywood and Boucher, 2000). However, the very low optical depths associated to periods characterized by such absorbing aerosols (winter season and pre-monsoon) are expected to moderate such a warming (e.g., Pant et al., 2006).

The CALIOP lidar profiles also revealed pollution from the IG plains to accumulate against the Himalayas, up to altitudes of $4-5 \mathrm{~km}$. With a minimum in the monsoon season, pollution (in the form of $\mathrm{BC}$ ) was regularly observed to be advected by mountain breeze to NCO-P (see also Marinoni et al., 2010). In fact, backtrajectories indicate the Nepal and northern India plains regions to represent the most common origin of PBL-influenced airmasses reaching the NCO-P all year round. In April and October, backtrajectories were found to originate in areas of maximum agricultural fires, possibly explaining the high levels of $\mathrm{BC}$ observed in these periods. Analysis of backtrajectory transits within the PBL also attributed long-range transport of mineral dust essentially to advection from the west Asian arid regions of the Thar and Takla Makan deserts, and of Tibet. Even though pre-monsoon and winter season backtrajectories reached over the Arabian, north African and European regions, no trajectories were found to originate in the boundary layer of these areas.

Acknowledgements. This study was carried out within the framework of the Ev-K2-CNR "SHARE-Stations at High Altitude for Research on the Environment" Project, in collaboration with the Nepal Academy of Science and Technology. We thank the AERONET for supporting the NCO-P instrument, and for providing the Ghandi College data. We thank the NOAA-Air Resource Laboratory for making HYSPLIT accessible to the research community. We also thank the NASA Langley Research Center Atmospheric Science Data Center for open distribution of the CALIPSO/CALIOP data, and NASA Goddard Earth Sciences Data Center for open distribution of the MODIS data.

Edited by: J. J. Schauer

\section{References}

Badarinath, K. V. S., Kharol, S. K., and Sharma, A. R.: Long-range transport of aerosols from agriculture crop residue burning in Indo-Gangetic Plains: A study using LIDAR, ground measurements and satellite data; J. Atmos. Sol.-Terr. Phys., 71, 112-120, 2009.

Bellouin, N., Jones, A., Haywood, J., and Christopher, S. A.: Updated estimate of aerosol direct radiative forcing from satellite observations and comparison against the Hadley Centre climate model, J. Geophys. Res., 113, D10205, doi:10.1029/2007JD009385, 2008.

Bonasoni, P., Laj, P., Angelini, F., Arduini, J., Bonafè, U., Calzolari, F. P., Cristofanelli, P., Decesari, S., Facchini, M. C., Fuzzi, S., Gobbi, G. P., Maione, M., Marinoni, A., Petzold, A., Roccato, F., Roger, J. C., Sellegri, K., Sprenger, M., Venzac, H., Verza, G. P., Villani, P., and Vuillermoz, E.: The ABC-Pyramid Atmospheric Research Observatory in Himalaya for aerosol, ozone and halocarbon measurements, Sci. Tot. Environ., 391, 252-261, 2008.

Bonasoni P., Laj, P., Cristofanelli, P., Sprenger, M., Decesari, S., Duchi, R., Angelini, F., Arduini, J., Bonafè, U., Calzolari, F., Colombo, T., Di Sarra, A., Evangelisti, F., Maione, M., Facchini, M. C., Fuzzi, S., Gobbi, G. P., Panday, A., Roccato, F., Sellegri, K., Venzac, H., Verza, G. P., Villani, P., Vuillermoz, E., and Marinoni, A.: Atmospheric Brown Clouds in the Himalayas: first two years of continuous observations at the Nepal-Climate Observatory at Pyramid (5079 m). Atmos. Chem. Phys., 10, 7515-7531, doi:10.5194/acp-10-7515-2010, 2010.

Carrico, C. M., Berginc, M. H., Shresthad, A. B., Dibbe, J. E., Gomesf, L., Harrisg, J. M.: The importance of carbon and mineral dust to seasonal aerosol properties in the Nepal Himalaya, Atmos. Env., 37, 2811-2824, 2003.

Charlson, R. J., Schwartz, S. E., Hales, J. M., Cess, R. D., Coakley, J. A., Hansen, J. E., and Hofmann, D. J.: Climate forcing, by anthropogenic aerosols, Science, 2, 55, 423-430, 1992.

Chinnam, N., Dey, S., Tripathi, S. N., and Sharma, M.: Dust events in Kanpur, northern India: Chemical evidence for source and implications to radiative forcing, Geophys. Res. Lett., 33, L08803, doi:10.1029/2005GL025278, 2006.

Cristofanelli, P., Bracci, A., Sprenger, M., Marinoni, A., Bonaf‘ e, U., Calzolari, F., Duchi, R., Laj, P., Pichon, J. M., Roccato, F., 
Venzac, H., Vuillermoz, E., and Bonasoni, P.: Tropospheric 25 ozone variations at the Nepal Climate Observatory-Pyramid (Himalayas, $5079 \mathrm{~m}$ a.s.1.) and influence of stratospheric intrusion events, Atmos. Chem. Phys., 10, 6537-6549, 2010, http://www.atmos-chem-phys.net/10/6537/2010/.

Dey, S., and Tripathi, S. N: Aerosol direct radiative effects over Kanpur in the Indo-Gangetic basin, northern India: Long-term (2001-2005) observations and implications to regional climate, J. Geophys. Res., 113, D04212, doi:10.1029/2007JD009029, 2008.

Dubovik, O. and King, M. D.: A flexible inversion algorithm for retrieval of aerosol optical properties from sun and sky radiance measurements. J. Geophys. Res., 105, 20673-20696, 2000.

Dubovik,O., Smirnov, A., Holben, B. N., King, M. D., Kaufman, Y. J., Eck, T. F., and Slutsker, I.: Accuracy assessments of aerosol optical properties retrieved from Aerosol Robotic Network (AERONET) Sun and sky radiance measurements, J. Geophys. Res., 105(D8), 9791-9806, 2000.

Dubovik, O., Holben, B., Eck, T. F., Smirnov, A., Kaufman, Y. J., King, M. D., Tanrè, D., and Slutsker, I.: Variability of Absorption and Optical Properties of Key Aerosol Types Observed in Worldwide Locations, J. Atmos. Sci., 59, 590-608, 2002.

Duchi, R., Cristofanelli, P., Marinoni, A., Calzolari, F., Angelini, F., Vuillermoz, E., Verza, G. P., and Bonasoni, P.: Two years of mineral dust transport observations at the Nepal Climate Observatory - Pyramid, Atmos. Chem. Phys. Discuss., in preparation, 2010.

Forster, P., Ramaswamy, V., Artaxo, P., Berntsen, T., Betts, R., Fahey, D. W., Haywood, J., Lean, J., Lowe, D. C., Myhre, G., Nganga, J., Prinn, R., Raga, G., Schulz, M., and Van Dorland, R.: Changes in Atmospheric Constituents and in Radiative Forcing, in: Climate Change 2007: The Physical Science Basis. Contribution of Working Group I to the Fourth Assessment Report of the Intergovernmental Panel on Climate Change, edited by: Solomon, S., Qin, D., Manning, M., Chen, Z., Marquis, M., Averyt, K. B., Tignor, M., and Miller, H. L., Cambridge University Press, Cambridge, UK and New York, NY, USA, 2007.

Guibert, S., Matthias, V., Schulz, M, Boesenberg, J., Eixmann, R., Mattis, I., Pappalardo, G., Perrone, M. R., Spinelli, N., and Vaughani, G.: The vertical distribution of aerosol over Europe synthesis of one year of EARLINET aerosol lidar measurements and aerosol transport modeling with LMDzT-INCA, Atmos. Environ. 39, 2933-2943, 2005.

Gautam, R., Liu, Z., Singh, R. P., and Hsu, C.: Two contrasting dust-dominant periods over India observed from MODIS and CALIPSO data, Geophis. Res. Lett., 36, L06813, doi:10.1029/2008GL036967, 2009.

Gobbi, G. P., Barnaba, F., and Ammannato, L.: The vertical distribution of aerosols, Saharan dust and cirrus clouds in Rome (Italy) in the year 2001, Atmos. Chem. Phys., 4, 351-359, doi:10.5194/acp-4-351-2004, 2004.

Gobbi, G. P., Kaufman, Y. J., Koren, I., and Eck, T. F.: Classification of aerosol properties derived from AERONET direct sun data, Atmos. Chem. Phys., 7, 453-458, doi:10.5194/acp-7-453-2007, 2007.

Haywood, J. and Boucher, O.: Estimates of the direct and indirect radiative forcing due to tropospheric aerosols: A review, Rev. Geophys., 38, 513-543, 2000.

Holben, B. N., Eck, T. I., Slutsker, I., Tanrè, D., Buis, J. P., Set- zer, A., Vermote, E., Reagan, J. A., Kaufman, Y. J., Nakajima, T., Lavenu, F., Jankowiak, I., and Smirnov, A.: AERONET - A federated instrument network and data archive for aerosol characterization, Remote Sens. Environ., 66, 1-16, 1998.

Kaufman, Y. J. and Fraser, R. S.: Light extinction by aerosols during summer air pollution; J. Appl. Meteor., 22, 1694-1706, 1983.

Kaufman, Y. J., Gobbi, G. P., and Koren, I.: Aerosol climatology using a tunable spectral variability cloud screening of AERONET data, Geophys. Res. Lett., 33, L07817, doi:10.1029/2005GL0254782006, 2006.

Koren, I., Remer, L. A., Kaufman, Y. J., Rudich, Y., and Martins, J. V.: On the twilight zone between clouds and aerosols, Geophys. Res. Lett., 34, L08805, doi:10.1029/2007GL029253, 2007.

Liu, Z., Liu, D., Huang, J., Vaughan, M., Uno, I., Sugimoto, N., Kittaka, C., Trepte, C., Wang, Z., Hostetler, C., and Winker, D.: Airborne dust distributions over the Tibetan Plateau and surrounding areas derived from the first year of CALIPSO lidar observations, Atmos. Chem. Phys., 8, 5045-5060, doi:10.5194/acp-85045-2008, 2008.

Marinoni, A., Cristofanelli, P., Duchi, R., Calzolari, F., Decesari, S., Sellegri, K., Laj, P., Vuillermoz, E., Verza, G. P., and Bonasoni, P.: Aerosol mass and black carbon concentrations at NCO-P, Atmos. Chem. Phys., 10, 8551-8562, doi:10.5194/acp-10-85512010, 2010.

Marcq, S., Laj, P., Roger, J. C., Villani, P., Sellegri, K., Bonasoni, P., Marinoni, A., Cristofanelli, P., Verza, G. P., and Bergin, M.: Aerosol optical properties and radiative forcing in the high Himalaya based on measurements at the Nepal Climate Observatory - pyramid site (5100 m a.s.1.), Atmos. Chem. Phys. 10, 5859-5872, doi:10.5194/acp-10-5859-2010, 2010.

Nakajima, T., Yoon, S., Ramanathan, V., Shi, G., Takemura, T., Higurashi, A., Takamura, T., Aoki, K., Sohn, B., Kim, S., Tsuruta, H., Sugimoto, N., Shimizu, A., Tanimoto, H., Sawa, Y., Lin, N., Lee, C., Goto, D., and Schutgens, N.: Overview of the Atmospheric Brown Cloud East Asian Regional Experiment 2005 and a study of the aerosol direct radiative forcing in east Asia, J. Geophys. Res., 112, D24S91, doi:10.1029/2007JD009009, 2007.

O’Neill, N. T., Eck, T. F., Smirnov, A., Holben, B. N., and Thulasiraman, S.: Spectral discrimination of coarse and fine mode optical depth, J. Geophys. Res., 108(D17), 4559, doi:10.1029/2002JD002975, 2003.

Pant, P., Hegde, P., Dumka, U. C., Sagar, R., Satheesh, S. K., Moorthy, K. K., Saha, A., and Srivastava, M. K.: Aerosol characteristics at a high-altitude location in central Himalayas: Optical properties and radiative forcing, J. Geophys. Res., 111, D17206, doi:10.1029/2005JD006768, 2006.

Prasad, A. K. and Singh, R. P.: Changes in aerosol parameters during major dust storm events (2001-2005) over the Indo-Gangetic Plains using AERONET and MODIS data, J. Geophys. Res., 112, D09208, doi:10.1029/2006JD007778, 2007.

Ramana, M. V., Ramanathan, V., Podgorny, I. A., Pradhan, B. B., and Shrestha, B.: The direct observations of large aerosol radiative forcing in the Himalayan region, Geophys. Res. Lett., 31, L05111, doi:10.1029/2003GL018824, 2004.

Ramanathan, V. and Crutzen, P.: New Directions: Atmospheric Brown "Clouds", Atmos. Env., 37, 4033-4035, 2003.

Ramanathan, V. and Carmichael, G. R.: Global and regional climate changes due to black carbon, Nature Geoscience, 1, 221-227, doi:10.1038/ngeo156, 2008. 
Ramanathan, V., Ramana, M. V., Roberts, G., Kim, D., Corrigan, C., Chung, C., and Winker, D.: Warming trends in Asia amplified by brown cloud solar absorption; Nature, 448, doi:10.1038/nature06019, 2007a.

Ramanathan, V., Li, F., Ramana, M. V., Praveen, P. S., Kim, D., Corrigan, C. E., Nguyen, H., Stone, E. A., Schauer, J. J., Carmichael, G. R., Adhikary, B., and Yoon, S. C.: Atmospheric brown clouds: Hemispherical and regional variations in long range transport, absorption and radiative forcing, J. Geophys. Res., 112, D22S21, doi:10.1029/2006JD008124, 2007b.

Satheesh, S. K. and Ramanathan, V.: Large differences in tropical aerosol forcing at the top of the atmosphere and Earth's surface, Nature, 405, 60-63, 2000.

Schwartz, S. E.: The whitehouse effect - shortwawe radiative forcing of climate by anthropogenic aerosols: an overview, J. Aeros. Sci., 27, 359-382, 1996.

Shrestha, A. B., Wake, C. P., Dibb, J. E., Mayewski, P. A., Whitlow, S. I., Carmichael, G. R., and Ferm, M.: Seasonal variations in aerosol concentrations and compositions in the Nepal Himalaya, Atmos. Env., 34, 3349-3363, 2000.
Smirnov, A., Holben, B. N., Eck, T. F., Dubovik, O., and Slutsker, I.: Cloud screening and quality control algorithms for the AERONET database, Remote Sens. Environ., 73, 337-349, 2000.

Tomasi, C.: Features of the scale height for particulate extinction in hazy atmospheres, J. Appl. Meteor., 21, 931-944, 1982.

Verma, S., Venkataraman, C., and Boucher, O.: Origin of surface and columnar Indian Ocean Experiment (INDOEX) aerosols using source- and region-tagged emissions transport in a general circulation model, J. Geophys. Res., 113, D24211, doi:10.1029/2007JD009538, 2008.

Wake, C. P., Mayewski, P. A., Zichu, X., Ping, W., and Zhongqin, L.: Regional distribution of monsoon and desert dust signals recorded in Asian glaciers, Geophys. Res. Lett., 20(14), 14111414, 1993.

Winker, D., Hunt, W., and McGill, M.: Initial performance assessment of CALIOP, Geophys. Res. Lett., 34, L19803, doi:10.1029/2007GL030135, 2007. 